\title{
Towards A Modified Framework for Informer Emancipation in Complex Contexts
}

\author{
Andrew M Connery and Helen Hasan \\ University of Wollongong, Wollongong, NSW, Australia
}

\author{
amc83@uowmail.edu.au hasan@uow.edu.au
}

\begin{abstract}
This paper addresses the tensions between rigid efficient systems that support the routine processes of productive institutions and the innovations required for the sustainable development of those institutions in changing dynamic complex environments. It examines the efforts of a mature age $\mathrm{PhD}$ student researcher with extensive business experience attempting to undertake action research on a disruptive technology within a conservative university context. The experience has motivated reflective research on the barriers to innovative communication in hierarchical institutions with silo-based legacy systems specifically designed to handle routinized information flows and support formalized decision-making. The student researcher then undertook an online review of intellectual property policies and related commercialization guidelines in universities throughout Australia which confirmed shortcoming in the suitability of such policies to encourage the engagement of business entities and/or private individuals wishing to undertake research with overt commercial outcomes. The findings lead to the development of a framework that may, if applied, help to overcome the widespread communication problems among those facing complex wicked problems in large and long established conservative institutions.
\end{abstract}

Keywords: dynamic complex systems, disruptive technology, informer emancipation framework

\section{Introduction}

Managing complexity within a dynamic and evolving system is a day to day challenge for all managers. There is a need to find a balance between the need to exploit existing resources with efficient, but rigid, information systems that support the routine processes of productive institutions and the imperative to explore new opportunities for innovation that will enable the sustainable development of those institutions in changing dynamic complex environments (March, 1991). This is particularly evident within larger organizations, such as universities, that should by their nature be fostering innovation and new knowledge while running an efficient stable business. The introduction of disruptive technologies that foster innovation should not preclude sufficient attention being paid to the sustaining tech-

Material published as part of this publication, either on-line or in print, is copyrighted by the Informing Science Institute. Permission to make digital or paper copy of part or all of these works for personal or classroom use is granted without fee provided that the copies are not made or distributed for profit or commercial advantage AND that copies 1) bear this notice in full and 2) give the full citation on the first page. It is permissible to abstract these works so long as credit is given. To copy in all other cases or to republish or to post on a server or to redistribute to lists requires specific permission and payment of a fee. Contact Publisher@,InformingScience.org to request redistribution permission. nologies that will allow the central core of the institution to maintain its favourable position in the marketplace (Christensen, 1995). There is a tendency by senior management to conserve and prefer existing proven practices and processes over the introduction of newer and perceived riskier or less profitable concepts or innovations. While this is clearly understandable, the real chal- 
lenge for organizations in the $21^{\text {st }}$ century wishing to remain productive and sustainable is to accommodate the tension between the exploitation of ordered process and systems, and the exploration of the innovation that comes with disruptive technology-based systems and unordered processes (March, 1991; Snowden, 1995).

Ideally, knowledge-focussed institutions such as universities must actively encourage a culture that is not only open to innovation but also tolerant of the inherent risk involved to optimize the outcomes of both approaches. However to do this they should implement more flexible information systems with formalized human intervention to handle non-routinized information and explorative projects.

The research described in this paper is motivated by the efforts of a mature age $\mathrm{PhD}$ student researcher with extensive business experience to undertake research on a disruptive technology within a university context. The student researcher's business has enjoyed a successful 10-year partnership with information systems researchers at the university involving collaboration applied research. Initially this involved a Master's research undertaking which investigated his innovative business model developed in implementing a commercially-operated community portal. This was completed in 2005. In 2008 he was accepted into a $\mathrm{PhD}$ program which would investigate the efficacy of the business's technology and procured an agreement to this effect in his doctoral research proposal. The technology (local community portal and service directory) was developed by his business and provisionally patented. Most significantly, the proposed research required temporary back-links from the university's website to the portal and directory sites owned by the student researcher's business in order to create a comprehensive data set for detailed analysis. This appeared to be relatively straight forward as the University website already had pages showcasing its local community engagement. If proven and patented this development would have massive commercial potential globally and favourably enhance the universities reputation.

At the beginning the research proceeded as outlined in the researcher's $\mathrm{PhD}$ proposal but efforts to proceed further met with objections when it came time to set up the required back-links. As will be described in the paper, this revealed the clash of two distinct cultures between what March (1991) refers to a need to exploit and the need to explore and what Snowden (1995) calls the 'ordered' and the "unordered'. The student's research was put on hold as unsuccessful attempts were made to resolve this. This clash of cultures was identified as a much more interesting research problem compared to the original one and the student's PhD now focuses on the problems emanating from the introduction of disruptive technologies into the bureaucratic environment of formal institutions such as universities despite their stated claims to be fostering innovation, etc. This is not an isolated case, e.g., MOOCS etc. (Armstrong, 2012) and points to a general phenomenon that is the topic of the research described here. However, as Christensen (1995) emphasizes, it is not technology by itself that makes an innovation disruptive - it is combining the technology with an optimized business model.

There is clearly a need the need for formal institutions to have policies and systems that support its routine process and activities. However, all institutions recognize that to be sustainable and prosperous there is an imperative to be innovative and have the flexibility to adapt to new circumstances. This represents a complex or 'wicked' problem. The term 'wicked problem' describes a group of persistent problems that have incompletely known and contradictory elements that are interconnected and constantly changing (Rittel \& Webber, 1973). In order to understand the complexity of this particular wicked problem the Cynefin sense-making theory has been adopted to underpin research into this phenomenon. Attempts to make sense of the communication breakdowns in this case has led to the development of a Modified Framework for Informer Emancipation (Figure C) building on the work of the Informing Science discipline and leveraging the framework developed by Cohen (2009). Using an action research approach the student researcher has examined how the use of email for all informing purposes can become the basis to creating an 
effective channel of communications. Whilst the framework architecture remains largely unchanged the innovative use of in-house electronic mail systems provides a robust, cost effective, trackable, and scalable repository for information that not only informs the client asynchronously but establishes a verifiable record of informing with legal status complete with temporal markers.

\section{Background}

The student researcher's business commenced the creation of a commercially funded online community portal in early 2001 and launched a community portal in May of that year with the financial support of several other local businesses.

The fledgling web-based business quickly became popular (Connery, 2006) and several innovations to monetize the portal were introduced including a weekly e-zine (of the same name) and a local online directory. A number of innovative advertising products were developed and tested both on the portal and e-zine however it was evident that advertisers much preferred year-long directory-type listings than casual banner advertisements. It also quickly became clear that monetizing the portal was much more of a challenge than simply creating a high traffic website.

The innovative endeavour attracted researchers in information systems at the university and a partnership developed attracting funds to study the project. In 2003 the business man became a student researcher, commencing a Master's Degree to investigate the sustainability of community portals world-wide. The researcher's thesis concluded that a sustainable platform to operate community portals had not been established anywhere in the world notwithstanding that the notion of operating a localized community portal was extremely popular and that the concept enjoyed considerable support from all levels of government.

The thesis speculated that a $3^{\text {rd }}$ generation network-type of community portal had the most potential of achieving sustainability and that Localised Search was an area of significant commercial opportunity which would benefit greatly from further development. The business's current funders were not prepared to resource this additional area of research and, as other competing industry partners declined to collaborate, the business owner financed the work himself, subsequently securing provisional patents in Australia and the US in mid-2008. Provisional Patents usually require proving within 12 months so the researcher was initially aiming to complete his research on overcoming search engine bias by mid-2009, subsequently extended 12 months to mid-2010. The business also approached universities in the areas the business operated portals and directories since they were the only neutral entities with sufficient online presence in terms of page rank that could assist prove his patents. It quickly became clear that small companies trying to undertake innovative research faced many hurdles most significantly the long delays in the decision-making processes and the inability to make presentations directly to relevant stakeholders.

Following representations from academic staff in late 2008 it was decided the businessman should undertake a $\mathrm{PhD}$ and that the required university resources to confirm the value of his provisional patents should be explicitly stated in the formal research proposal and a participatory action research methodology adopted.

Notwithstanding a long and mutually rewarding association of the student's business with the university and the full support of all academic staff, the researcher was unable to progress his $\mathrm{PhD}$ studies due to the refusal of the university's IT Services division to allow the required temporary back-links from the university's website to the portal and directory sites owned by the student's business. This simple link was also required to increase the target website's page rank to gather sufficient data in time for the researcher's $\mathrm{PhD}$ thesis and this had been specifically included in his approved $\mathrm{PhD}$ proposal. The student researcher sent many requests by email to argue his case and pursued all formal avenues available to him as a student to complete his research. 
Over the time taken for this process the student researcher lost his provisional Australian and US patents and was unable to complete his doctoral thesis as planned. As the dispute continued the student came to the realization that this experience had uncovered a wicked problem in the impact of disruptive technologies on traditional institutions, namely the conflict between an institutions espoused support for innovation through action research in other organizations and its reluctance to allow this practice itself. The student researcher decided to resume his $\mathrm{PhD}$ study making this contradiction the topic of his research.

\section{Research Design}

The methodology adopted for this research begins with a case conducted as action research closely following the researcher's experience over three years starting with a background to his business and outlines early commercial and academic research. This is written up as a case which identifies the research problem and describes its characteristics as a wicked problem. Secondary cases of similar problems have been identified including the introduction of Executive Information Systems (Hasan \& Gould, 2001), the introduction of a user driven timetabling systems (Hasan \& Suratmethakul, 2005) and more recently the introduction of MOOCs (Armstrong, 2012). A full presentation of these secondary cases is beyond the scope of this paper. The Cynefin sense-making framework (Snowden, 2005) is adopted as an analytical lens due to the complex nature of these wicked problems. A review of how other tertiary institutions handle research student Intellectual Property (IP) is included together with a suggested modified framework (Figure C) to overcome the communications problems encountered in the primary case.

The phases of the research reported here are

1. The initial attempt to conduct action research on Ranking Websites in a Community Portal (see Background above)

2. A reflection on the failure of this attempt using the Cynefin sense-making framework and identifying a more general significant problem

3. A survey of the espoused IP policies of other institutions

4. The justification for, and development of, a frame work for the emancipation of the informer driving innovation through disruptive technologies in a traditional risk averse institution.

As Phase 1 is covered in the Background section of the paper, the findings of Phases 2-4 will now be described

\section{Phase 2: Reflecting on the Wicked Problem}

From the student researcher's experience of the primary case, he surmised that when it comes to non-routinized requests the existing university's information and decision-making systems are deficient in a number of areas:

1) They are designed purely for routinized functions and are seemingly unable to handle any requests that do not meet their legacy system's exact requirements.

2) Although all documents are eventually filed in secure repositories and become accessible by authorized parties they are not in fact reviewed or audited for completeness or accuracy.

3) There are no formal human-based review systems of any substance in place.

4) There is no automatic commitment to official university goals, visions, or rhetoric. 
5) Non-routine requests that do in fact meet corporate goals can be declined or ignored by administrative staff without reason and/or review.

6) Administration staff can overrule academics on research issues which can only be fully understood by academic staff.

7) students do not have any access or rights to be considered on any decisions which directly impact on their research.

The researcher's difficulties in attempting to inform the university of the situation could be considered as a symptom of a more general wicked problem, i.e., a problem whose solution requires a great number of people to change their mindsets and behaviour. According to Conklin (2006) the defining characteristics of wicked problems are:

1. The problem is not understood until after the formulation of a solution.

2. Wicked problems have no stopping rule.

3. Solutions to wicked problems are not right or wrong.

4. Every wicked problem is essentially novel and unique.

5. Every solution to a wicked problem is a 'one shot operation.'

6. Wicked problems have no given alternative solutions.

The researcher was impressed by the potential contribution of the Cynefin (pronounced kunev'in) framework to act as an analytical tool for his research tasks. The Cynefin model (Snowden, 1995) started life as a sense-making framework not a categorisation model although now it is often used as such. In a sense-making model the framework emerges from the data, while in categorisation the model is imposed on the phenomenon of interest.



Figure A: The Cynefin Framework 
The Cynefin framework (Figure A) consists of five domains: two of 'order' (the known and the knowable), two of 'unorder' (complexity and chaos) and one of 'disorder'. Wicked problems cross all domains but are most appropriately understood in the complex domain.

This research focuses on the clash between the ordered domains, where organisational s processes are similar to March's (1991) concept of exploitation, and the 'unordered' domains where exploration is appropriate. In some respects these domains signify what in information systems are variously referred to as different worldviews, epistemological stances, or paradigms that make it difficult to present situations and problems from one coherent perspective (Hasan \& Kazlauskas, 2009).

In the originally proposed research an ordered 3 Step Methodology was planned and included in his $\mathrm{PhD}$ proposal. All steps were to be sequential and each new step would not commence until the prior step had been in place for at least six weeks and had not created problems of any kind for the host university. His subsequent experiences showed a great deal of 'unorder'.

On reflection the student researcher now views his project within Cynefin's emergent complex domain (Figure A) where, with minimal support in the form of temporary back links, he could test the new technologies he was incorporating on his community portal. Those who refused to allow this appear to be operating in the completely 'ordered' domains where no untried innovation was allowed. There was definitely a clash between the ordered culture of university administration and the unordered world of innovative research particularly where disruptive technologies are involved. With the university's legacy information system it is not possible for an Informer to know whether his or her communication is actually received, or not, by the client and it is this glaring deficiency, so easily accommodated by using a modern email system, this paper addresses in Phase 4.

\section{Phase 3: A Survey of IP Policies}

The student researcher was always aware of the difficulties involved in dealing with a large institution such as a university and sensitive to the added complexity of involving a disruptive technology Christensen (1995) however he was always optimistic that common sense would prevail particularly with research which so clearly met all the university's stated goals and visions. In particular, as outlined in AUCEA (2006) Position Paper regarding Universities and Community Engagement under the heading Purpose, "university-community engagement specifically implies collaborative relationships leading to productive partnerships that yield mutually beneficial outcomes. A university's communities can include many groups such as businesses, industries, professional associations, schools, governments, alumni, indigenous and ethnic communities as well as groups of local citizens. Engagement is therefore a core activity of a university and should not be considered a separate undertaking". Community engagement should be a key component in a university's staff promotion and performance review programs and feature in the annual Assessment Framework Information Collection. The university where he enrolled espoused strong support for community engagement and innovative technology-based research. However when it came to an innovative community project such as his, those at the operational decision-making level seemed quite ignorant of the role that student researchers could play here.

An online examination of the IP policies of Australian, and some leading US, universities (Table A) reveals a wide divergence in the documentation of student intellectual property (SIP) and does not clearly differentiate between whether it is created as part of a university sponsored research project, solely by the student's personal endeavours while enrolled or developed prior to the commencement of study. 
Table A: A Comparison Of IP Policies Available Online as at JAN 2014

\begin{tabular}{|c|c|c|c|}
\hline University & $\begin{array}{c}\text { Student } \\
\text { IP Disclosure }\end{array}$ & $\begin{array}{c}\text { Creator } \\
\text { Distribution }\end{array}$ & $\begin{array}{c}\text { Funding } \\
\text { for Start-ups }\end{array}$ \\
\hline UOW & $\begin{array}{l}\text { Via Intranet only } \\
\text { since } 2006\end{array}$ & $50 \%$ & $\begin{array}{l}\text { Deed of Assignment No stu- } \\
\text { dent share-holding Royalty } \\
\text { only }\end{array}$ \\
\hline UWS & $\begin{array}{l}\text { Yes - Public ex web } \\
\text { Students own IP }\end{array}$ & $\begin{array}{l}100 \% \text { then } 33 \% \\
\text { if applicable }\end{array}$ & $\begin{array}{l}\text { No Published } \\
\text { Information }\end{array}$ \\
\hline UTS & $\begin{array}{l}\text { Background Intellectual } \\
\text { Property Statement }\end{array}$ & $\begin{array}{l}100 \% \text { then } 50 \% \\
\text { if applicable }\end{array}$ & $\begin{array}{l}\text { Supports } \\
\text { Accelerator }\end{array}$ \\
\hline NSW (G8) & $\begin{array}{l}\text { Students own IP } \\
\text { since } 2004\end{array}$ & $\begin{array}{l}100 \% \text { then } 33 \% \\
\text { if applicable }\end{array}$ & $\begin{array}{l}\text { Supports } \\
\text { Accelerator }\end{array}$ \\
\hline $\begin{array}{l}\text { SYDNEY } \\
\text { (G8) }\end{array}$ & $\begin{array}{l}\text { Students own IP } \\
\text { Rule } 2002\end{array}$ & $\begin{array}{l}100 \% \text { then } 33 \% \\
\text { if applicable }\end{array}$ & $\begin{array}{l}\text { No Published } \\
\text { Information }\end{array}$ \\
\hline ANU (G8) & Nil & $\begin{array}{c}35 \% \\
\text { if applicable }\end{array}$ & $\begin{array}{l}\text { ANU Connect Ventures up to } \\
\$ 500,000 \text { per enterprise }\end{array}$ \\
\hline $\begin{array}{l}\text { MONASH } \\
\text { (G8) }\end{array}$ & Invention Disclosure Form & $\begin{array}{c}30 \% \\
\text { if applicable }\end{array}$ & $\$ 10-50 \mathrm{~K}$ \\
\hline $\begin{array}{l}\text { MEL- } \\
\text { BOURNE } \\
\text { (G8) }\end{array}$ & $\begin{array}{c}\text { Students own IP } \\
\text { Other than for Teaching } \\
\text { Materials }\end{array}$ & $\begin{array}{l}100 \% \text { then } 40 \% \\
\text { if applicable }\end{array}$ & $\begin{array}{l}\text { No Information AngelCube } \\
\text { Seed Investment up to } \\
\$ 20 \mathrm{~K}\end{array}$ \\
\hline $\begin{array}{l}\text { QUEENS- } \\
\text { LAND (G8) }\end{array}$ & Invention Disclosure Form & $\begin{array}{c}33 \% \\
\text { if applicable }\end{array}$ & No Published Information \\
\hline $\begin{array}{l}\text { ADELAIDE } \\
\text { (G8) }\end{array}$ & Students own IP & $\begin{array}{l}100 \% \text { then } 33 \% \\
\text { if applicable }\end{array}$ & $\begin{array}{l}\text { Accelerator } 3 \text { month courses } \\
\text { funding up to } \$ 18 \mathrm{~K}\end{array}$ \\
\hline $\begin{array}{l}\text { WESTERN } \\
\text { AUSTRALIA } \\
(\mathrm{G} 8)\end{array}$ & Invention Disclosure Form & $\begin{array}{l}100 \% \text { or other } \\
\text { by agreement }\end{array}$ & No Published Information \\
\hline HARVARD & Disclosure since 1975 & $35 \%$ & No Published Information \\
\hline STANFORD & OTL online disclosure & $28 \%$ & StartX to match VC funding \\
\hline MIT & TLO online disclosure & $28 \%$ & DRF $\$ 20 \mathrm{~K}$ \\
\hline
\end{tabular}

IP disclosure upon enrolment is not uniform across universities and there does not appear to be any reason why SIP could not be treated consistently throughout the country and related documentation made available when a student transfers between universities. In fact, based on the researcher's experience, all parties would greatly benefit from such an initiative.

The distribution of royalties or license fees to the creator of SIP also varies significantly between institutions for no apparent reason. Consistency in this policy area is also recommended. 
The prospect for universities to fund start-ups commercializing SIP also appears to be ad hoc and the temporal constraints imposed - in the university this paper relates to 18 months was allowed for the administration to decide if the university wished to participate and the SIP would be effectively embargoed till the decision was forthcoming.

In the case of a student researching disruptive technologies at any university due to the speed of technology adoption generally this type of requirement is both totally unreasonable and difficult to justify.

Given the well-known challenges to discovering and commercializing innovative and/or disruptive technologies it would seem desirable that all government funded research institutions take steps to remove any non-helpful artificial barriers hindering progress, starting with a review of the treatment of SIP, and the discipline of Informing Science could play a significant role in this initiative.

\section{Phase 4: A Modified Framework for Informer Emancipation}

In an effort to make sense of the dispute in the primary case the student research turned to the Informing Science framework (Cohen, 2009) shown in Figure B. Whilst being a comprehensive characterization of information flows generally, it does not reflect either the current role played by e-mail or its potential to improve organizational outcomes by more fully utilizing the range of capabilities already inherent in the now ubiquitous electronic medium together with timely judicious human intervention when circumstances dictate in an on-going iterative process.

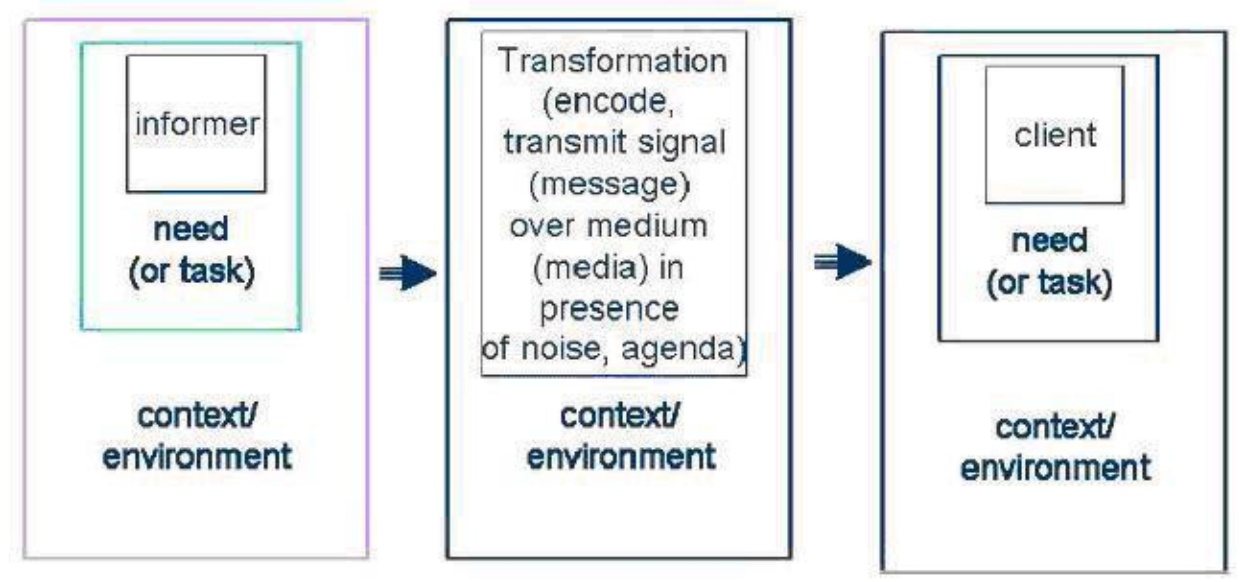

Figure $B$

Figure B: Cohen's Informing Science framework

The researcher's problems with informing / communication are at the core of the problems he faced interfacing with the university and can be summarized as:

1) The university's legacy information system was designed only for routinized information flow and was deficient for this primary purpose since the university had no means of ascertaining the semantic sense of responses, i.e., the input could be nonsensical so long as some data was placed in the relevant field/s 
2) The well known silo approach ensured that critical information or policy settings of the administration were not included in the academic information systems, i.e., no overlap

3) The legacy system has no capacity to handle non-routinized information either by creating a log of non-conforming responses or automatically flagging responses or complaints that require human intervention of some kind

4) The university has no capability to pro-actively monitor, filter, or process information flows other than within its own internal systems, i.e., relevant emails or other digital artefacts are not directly accessible, collated, or linked in any fashion

5) The university did not appear to have a satisfactory Intellectual Property Disclosure policy in place, at least not one publically available to students.

The proposed modified framework (Figure C) empowers informers by incorporating feedback flows to overcome the systemic inertia so evident in multi-level silo-based bureaucracies by ensuring inappropriate action or inaction by client decision-makers is not rewarded or legitimized and that higher organizational goals are achieved.



Figure $\mathrm{C}$

Figure C: A Modified Framework for Informer Emancipation

In the $21^{\text {st }}$ century transparency in organizational decision-making and the delivery of natural justice to all levels within a large organization should be mandatory (Astor, 2008). To that end all information systems should be designed to identify and act upon mis-aligned or sub-optimal management practices and to enhance organizational performance generally.

To significantly improve the discipline of Informing Science within a large organization requires the implementation of some basic protocols or heuristic routing and, if not currently available, the establishment of an ombudsman and a decisions review body. The protocols would formalize the required form of inter-organizational communication which could in some instances be directly coded into existing systems or simply installed as pre-set email preferences. 
The minimum requirements would include:

1) As a default all communications should be by email and if verbal in the first instance subsequently confirmed by email. This approach ensures a digital trail is created and embeds annotations, specifically temporal markers, which have legal status.

2) Any informer requests for action or resources that appear to comply with an organization's policy guidelines should be granted within a reasonable (or nominated) time; alternatively an explanation by the client should be given by email explaining why the request was not granted. Where requests are considered by committees all related minutes or motions should upon request be provided to the informer at no cost and within a reasonable time.

3) After a time lapse non-responses should be forwarded by default to a senior administrator who will either intervene to expedite the original request or report on a regular (say monthly) basis to the head of administration why non-action was appropriate together with recommendations including referral to an ombudsman or review body.

4) The informer should be able to seek a review of unsatisfactory explanations (see $2 \& 3$ ) and also have the right to appear at any review body personally and/or with an ombudsman acting for them.

5) Where non-public policies or guidelines are used by clients as justification for the denial of requests copies of the relevant documents should be made available to the informer upon request. When the interpretation by clients is at odds with stated organizational goals or policies the matter should be referred to a senior administrator who will advise the informer what further steps may be in order and/or grant an appointment.

\section{Discussion and Conclusions}

As previously stated, managing complexity within a dynamic and evolving system is an on-going day to day challenge for all managers and particularly those within larger organizations, such as universities, that should by their nature be fostering innovation and new knowledge.

In complex systems, unpredictability and paradox are ever present, and some things will remain unknowable. New conceptual frameworks that incorporate a dynamic, emergent, creative, and intuitive view of the world must replace traditional 'reduce and resolve' approaches (Plsek \& Greenhalgh, 2001).

The increasing importance being placed on innovation in the wider economy and its potential to improve productivity and create new jobs still receives uncritical support generally. What appears to escape examination is the role universities should be playing to deliver these desired outcomes. It would seem the focus on simply producing large numbers of qualified graduates should be coupled with metrics that measure the rate of adoption of innovation within institutions, e.g., the number of patents registered by university research students - i.e., not employed research staff.

The area of financing student start-ups within universities is beyond the scope of this paper but is also an issue which requires urgent attention if Australia is to seriously compete on a global stage.

Given the researcher's experience it would seem that whilst adopting a Cynefin based approach to handling complexity is currently best real world practice implementing this model cannot on its own overcome the significant hurdles that are inherent in out-dated legacy information systems so common in large tertiary educational institutions. 
The researcher believes the implementation of the five minimum requirements embodied in the Researcher's Modified Framework for Inquirer Emancipation should be seen as an integral part of the solution to managing complexity in a multi-level organization.

However the role of timely human intervention and judicious decision-making cannot be over emphasized and the introduction of policies and guidelines that entrench its importance in the informing science process should be implemented as soon as practicable.

Managing complexity is a field that fits neatly within the Informing Science discipline and uncomfortably with just about all other disciplines as a consequence further research in this area to build on both Snowden and Cohens' seminal work along the lines suggested in the researcher's modified framework is highly recommended.

In the primary case the strong and on-going relationship of the student researcher with academic staff and their total support for the intended research convinced the researcher that his commercially oriented research would ultimately succeed to the benefit of all and that any covert administrative difficulties or cultural issues the university might have should be identified, addressed, diligently pursued, and eventually overcome.

The five year long experience has highlighted the difficulties likely to be encountered by any student trying to pursue innovative research at a university. The experience strongly suggests that existing small businesses will likely face similar obstacles trying to engage with their local universities. Clearly neither of these research outcomes aligns with what the tertiary education sector would wish for and both are in stark contrast with the university's own goals, vision, policies, and rhetoric.

It is recommended that all universities should implement policies such as outlined in the Modified Framework for Emancipation as a matter of urgency and the discipline of Informing Science should communicate this view to its members and all institutions of higher learning in this country.

Further research is strongly recommended in this area which has obvious benefits to the economy generally and particularly in the field of improvement of efficiency in larger organizations of all kinds.

\section{References}

Astor, H. (2008). Australian universities in court: The causes, costs and consequences of increasing litigation. Australasian Dispute Resolution Journal, 19(3), 156-169.

AUCEA. (2006). Position paper: Universities \& community engagement. Retrieved Jan 2014 from http://www.universityworldnews.com/filemgmt data/files/AUCEA\%20Position\%20Paper.pdf

Armstrong, L. (2012). Coursera and MITx: Sustaining or disruptive? Retrieved Jan 2014 from http://www.changinghighereducation.com/2012/08/coursera-.html

Christensen, C. M. (1995). Disruptive technologies: Catching the wave. Retrieved January 2014 from http://hbr.org/1995/01/disruptive-technologies-catching-the-wave/

Cohen, E. (2009). A philosophy of informing science. Informing Science: the International Journal of an Emerging Transdiscipline, 12, 1-15. Retrieved January 2014 from http://inform.nu/Articles/Vol12/ISJv12p001-015Cohen399.pdf

Conklin, J. (2006). Dialogue mapping: Building shared understanding of Wicked Problems. Chichester, England: Wiley Publishing. ISBN 0470017686.

Connery, A. (2006). An examination of the sustainability of online communities in Australia including the findings of participatory action research undertaken on a beta $3^{\text {rd }}$ generation network type regional community portal in New South Wales. Masters Thesis, University of Wollongong. 
Hasan, H., \& Gould, E. (2001). Support for the sense making activity of managers. DSS Journal, special issue on Knowledge Management, 31(3), 71-86.

Hasan, H., \& Kazlauskas, A.(2009). Making sense of IS with the Cynefin frame work. Retrieved January 2014 from http://ro.uow.edu.au/cgi/viewcontent.cgi?article=2008\&context=commpapers

Hasan, H., \& Suratmethakul, W. (2005). The challenges of introducing off-the-shelf systems into complex work organisations, Proceedings of ECIS2005, Regensburg.

March, J. G. (1991). Exploration and exploitation in organizational learning. Organization Science, 2(1), 71-87.

Plsek, P. E., \& Greenhalgh, T. (2001). Unpredictability and paradox in complex systems. Retrieved January 2014 from http://www.bmj.com.ezproxy.uow.edu.au/content/323/7313/625

Rittel, H., \& Webber, M. (1973). Dilemmas in a general theory of planning. Policy Sciences, 4, 155-169. Retrieved Jan 2014 from http://www.uctc.net/mwebber/Rittel+Webber+Dilemmas+General_Theory_of Planning.pdf

Snowden, D. (1995). Cynefin as a framework. Retrieved January 2014 from http://cognitiveedge.com/library/more/video/introduction-to-the-cynefin-framework/

\section{Biographies}

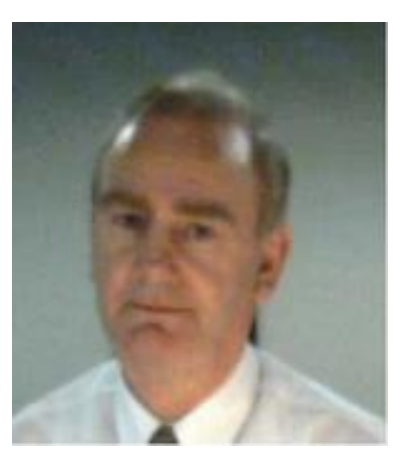

Andrew M Connery, a pioneer in social media and active online since early 2001, heads up the editorial team of WollongongOnline.com and is currently undertaking doctoral research on disruptive technologies at the University of Wollongong. A B2B marketing practitioner by profession his specialty area is local online search and until July 2011 he was a Senior Trainer for the Federal Government's Small Business Online program.

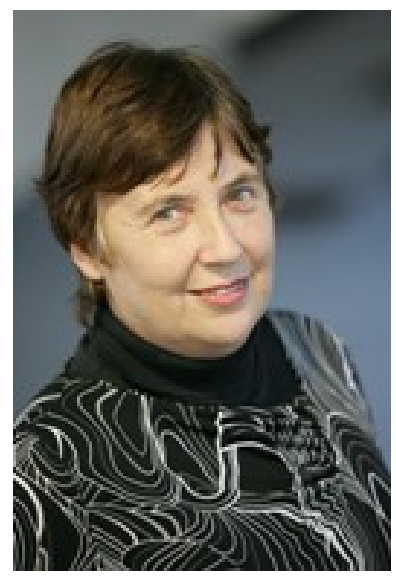

Dr Helen Hasan is Associate Professor of Information Systems (IS) at the University of Wollongong where she directs the THEORI Research Centre and the Social Innovation Network who's 'Grey' and 'Green' Themes dominate her current interests. Her 'Grey' projects investigate the use of IT by the elderly for their social wellbeing. She leads local, national and international special interest groups on Green IS. In 2012, Helen received the Vice -Chancellor's Award for Research Student Supervisor of the year. 